\title{
A CIRCULAÇÃO DO \\ CONHECIMENTO LINGUÍSTICO \\ NA REVISTA BRASILEIRA \\ DE FILOLOGIA
}

\section{LA CIRCULACIÓN DEL CONOCIMIENTO LINGÜÍSTICO EN LA REVISTA BRASILEIRA DE FILOLOGÍA}

\author{
THE CIRCULATION OF LINGUISTIC KNOWLEDGE IN THE REVISTA BRASILEIRA DE \\ FILOLOGIA
}

Caroline Mallmann Schneiders*

Universidade Federal da Fronteira Sul

\begin{abstract}
RESUMO: No presente estudo, refletimos sobre a importância das revistas científicas para a circulação e a legitimação do conhecimento científico. Para tanto, mobilizamos, como objeto de reflexão, a Revista Brasileira de Filologia, uma revista representativa que circulou a partir de meados dos anos de 1950 e início de 1960, no âmbito do contexto nacional brasileiro. Tendo em vista tal revista científica e a conjuntura sócio-histórica de sua circulação, analisamos como essa materialidade discursiva contribui para a legitimação de determinados domínios de saber, como: da Filologia, da Linguística e da Dialetologia. Nosso objetivo principal é, pois, compreender como essa revista, dita especializada, influencia e contribui para o estabelecimento e a constituição do conhecimento linguístico tanto no contexto nacional como no sul do Brasil. O desenvolvimento desse estudo está filiado aos pressupostos teóricos da História das Ideias Linguísticas e da Análise de Discurso de linha pecheuxtiana, tal como ambas se desenvolvem no Brasil.
\end{abstract}

PALAVRAS-CHAVE: Circulação. Conhecimento. Filiação. Efeitos de sentido.

RESUMEN: En el presente estudio, reflexionamos sobre la importancia de las revistas científicas para la circulación y la legitimación del conocimiento científico. Para ello, tomamos como objeto de reflexión, la Revista Brasileira de Filologia, una revista representativa que circuló desde los años 50 hasta inicio de los 60 en el ámbito del contexto nacional brasileño. Teniendo en cuenta tal revista científica y la coyuntura sociohistórica de su circulación, analizamos como esa materialidad discursiva contribuye para la legitimación de determinados dominios de saber, tales como: de la Filología, de la Lingüística y de la Dialectología. El principal objetivo nuestro es, pues, comprender como esa revista, dada por especializada, influye y contribuye al establecimiento y la constitución del conocimiento científico tanto en el contexto nacional como en el sur de Brasil. El desarrollo de ese estudio se basa en los teóricos de la Historia de las Ideas Lingüísticas y del Análisis del Discurso, de línea pecheuxtiana, tal como ambas se desarrollan en Brasil.

PALABRAS CLAVE: Circulación. Conocimiento. Filiación. Efectos de sentido.

*Mestra e doutora em Estudos Linguísticos pela Universidade Federal de Santa Maria. Professora Adjunta de Língua Portuguesa e Linguística do Curso de Graduação em Letras Português e Espanhol, na Universidade Federal da Fronteira Sul,campusCerroLargo/RS.E-mail:caroline.schneiders@uffs.edu.br. 
ABSTRACT: In this study, we reflect upon the importance of scientific journals for the circulation and the legitimation of scientific knowledge. For this purpose, we gathered as object the Revista Brasileira de Filologia, a representative journal that circulated between the 1950s and early 1960s under the Brazilian national context. In view of this journal and the socio-historical context of its circulation, we analyzed how this discursive materiality has contributed to the legitimacy of certain areas of knowledge, such as Philology, Linguistics and Dialectology. Therefore, our main goal is to understand how this journal influences and contributes to the establishment and constitution of linguistic knowledge both in the national context and in southern Brazil. The development of this study is affiliated to the theoretical assumptions of the History of Linguistic Ideas and Pêcheux's Discourse Analysis, as both are developed in Brazil.

KEYWORDS: Circulation. Knowledge. Affiliation. Effects of meaning.

\section{PALAVRAS INICIAIS}

[...] as publicações periódicas vão indicando os novos rumos das pesquisas, debatendo os problemas, renovando os métodos, expondo as discussões teóricas e fazendo a crítica dos livros da especialidade.

(Serafim da Silva Neto, In: RBF, Vol. I - Tomo 1, 1955, p. 1)

As revistas científicas cumprem um papel fundamental tanto no processo de comunicação da ciência como na legitimação do conhecimento científico. Tratam-se de produções que começaram a ser publicadas no século XVII, na Europa, configurando-se como uma prática vinculada a determinado período sócio-histórico e ideológico, com vistas a atender às demandas científicas da época.

Segundo Stumpf (1996), as revistas científicas constituem-se como uma "[...] evolução do sistema particular e privado de comunicação que era feito por meio de cartas entre os investigadores e das atas ou memórias das reuniões científicas" (STUMPF, 1996, paginação irregular). Como sabemos, a correspondência pessoal foi um importante meio utilizado entre os estudiosos para a discussão de ideias.

No Brasil, considerando a prática da vida intelectual entre os homens de letras, temos vários exemplos sobre o funcionamento e a importância que as correspondências tiveram, como é o caso da epistolografia de Mário de Andrade, cujo funcionamento discursivo pode ser observado no estudo desenvolvido por Buscácio (2014). Dessa forma, a correspondência, enquanto 'materialidade significante', também se torna um interessante objeto de estudo para se observar o processo de constituição e legitimação do conhecimento científico.

É importante destacar que, mesmo havendo esse movimento das correspondências para a publicação de revistas científicas, as correspondências continuaram - e talvez continuem pensando hoje nas novas formas de correspondências via novas tecnologias a exercer um papel central para a discussão e comunicação da ciência. Aos poucos, as revistas ou periódicos científicos instalaramse por toda a Europa, geralmente vinculando-se às sociedades e academias científicas. Desse modo, no século XVIII, surgem também, mas de uma forma generalizada, os periódicos científicos especializados, referentes a campos específicos do conhecimento. E é, sobretudo no século XIX, que vemos uma intensificação na produção das revistas científicas, em função do crescimento do número de pesquisas e pesquisadores.

Tal intensificação permaneceu no século XX, devido ao fato de as revistas passarem a ser publicadas por editores comerciais, pelo Estado e por Universidades. De acordo com Stumpf (1996, paginação irregular), "[...] a partir da segunda metade [do século XX], especialmente as publicações seriadas tiveram um crescimento exponencial, intensificando também o seu controle bibliográfico"1.

${ }^{1}$ Um percurso histórico mais detalhado sobre o desenvolvimento dos periódicos científicos pode ser verificado em Stumpf (1996). 
Partindo dessa importância que as revistas científicas possuem tanto para a divulgação como para a legitimação do conhecimento científico, interessa-nos refletir, neste estudo, sobre o funcionamento discursivo da Revista Brasileira de Filologia (RBF), uma revista representativa que circulou a partir de meados dos anos de 1950 e início de 1960, no âmbito do contexto nacional brasileiro. Tendo em vista tal revista científica e a conjuntura sócio-histórica de sua circulação, buscamos analisar como essa materialidade discursiva contribui para a legitimação de determinados domínios de saber, em especial, da Filologia, da Linguística e da Dialetologia. Diante disso, nosso objetivo principal é compreender como essa revista, dita especializada, como observamos pelo seu título, Revista Brasileira de Filologia, influencia e contribui para o estabelecimento e a constituição do conhecimento linguístico tanto no contexto nacional como no sul do Brasil. Para tanto, filiamo-nos aos pressupostos teóricos da História das Ideias Linguísticas e da Análise de Discurso, tal como ambas se desenvolvem no Brasil.

\section{AS REVISTAS CIENTÍFICAS E A CIRCULAÇÃO DO CONHECIMENTO}

Stumpf (1997) destaca que "[...] comunicar a ciência é transferir os conhecimentos gerados pela investigação científica” (STUMPF, 1997, p. 46). Desse modo, a autora aponta para a importância das publicações, as quais possibilitam que o conhecimento seja registrado e divulgado, podendo, assim, ser utilizado pela comunidade científica. As publicações constituem-se, dessa forma, "[...] tanto insumo básico quanto produto final da atividade científica” (STUMPF, 1997, p. 46).

Nesse sentido, consideramos que as publicações permitem a comunicação científica, a qual, no entender de Costa (2008), é imprescindível para o avanço e o desenvolvimento da ciência. Por meio dessa comunicação, não há apenas a divulgação do conhecimento, mas também a relação entre o conhecimento e a comunidade científica, e esta, por sua vez, contribui para a legitimação do saber entre seus pares.

Para a autora, os periódicos científicos configuram-se, pois, como os principais modos de veiculação da comunicação científica e têm, em especial, três funções distintas, a saber:

1. ser arquivo da ciência, pois registam de forma permanente as descobertas e avanços científicos;

2. ser veículos de divulgação e comunicação do saber, uma vez que é através deles que o conhecimento fica disponível à comunidade;

3. ser meios de conferir prestígio e reconhecimento aos autores, pois os artigos são avaliados pelos pares antes de serem publicados. (COSTA, 2008, p. 18).

Na reflexão que propomos acerca da RBF, buscamos levar em conta tais aspectos constitutivos dos periódicos, mas considerando-a como uma revista científica. Destacamos a qualificação "científica" junto ao nome "revista", devido à discussão existente sobre a definição que pode ser adotada acerca dessa materialidade: "periódicos científicos” ou "revistas científicas”. Segundo Stumpf (1998, p.3)

[...] o uso dos termos "periódicos científicos" ou "revistas científicas" é diferenciado pelo tipo de profissionais que os utilizam. Os bibliotecários preferem a denominação "periódicos científicos", utilizando esta forma de expressão como termo técnico. Já os pesquisadores, cientistas, professores e estudantes preferem a denominação "revistas científicas". Este grupo muitas vezes nem se preocupa em qualificar o termo "revistas" pelo adjetivo "científicas", considerando que o próprio ambiente acadêmico em que estas publicações são usadas dispensa esta qualificação.

Partindo dessa discussão e considerando que a RBF é uma publicação vinculada à Livraria Acadêmica, editora importante da época, ou seja, uma publicação que não se filia diretamente ao âmbito institucional da Academia, em nosso estudo, entendemos que se torna necessário qualificar a RBF como 'revista científica'. Outro ponto importante que se coloca quando refletimos sobre essa qualificação são as condições históricas de produção, já que estas determinam/afetam a constituição da materialidade. 
Além disso, devemos considerar que há a determinação institucional, conforme destaca Guimarães (2004), a qual particulariza a produção do conhecimento e a sua circulação. Para o autor, o "[...] conhecimento é produzido por práticas específicas de profissionais específicos" (GUIMARÃES, 2004, p. 15), que são constituídos por um processo histórico e ideológico e que, "[...] para produzirem conhecimento, se acham individualizados pelas instituições a que estão vinculados” (GUIMARÃES, 2004, p. 16). Assim, embora a RBF esteja vinculada a uma editora e não propriamente a alguma instituição acadêmica, podemos dizer que há, sim, uma relação institucional constitutiva dessa materialidade, a qual pode ser observada a partir de quem funda/organiza essa revista científica e de quem publica no seu interior, permitindo-nos compreender as relações institucionais estabelecidas e as relações entre os pares da comunidade científica.

Tendo em vista essas questões e o fato de as revistas científicas proporcionarem não só a comunicação científica, mas também a produção do conhecimento, partimos do pressuposto que elas não se situam fora da história nem das relações institucionais a que se vinculam e que individualizam os 'profissionais específicos' que aí publicam. Por esse viés, as revistas científicas, assim como a produção do conhecimento, configuram-se enquanto uma "prática histórica, materialmente determinada”, constituída por sujeitos situados “[...] ideologicamente em condições históricas específicas” (GUIMARÃES, 2004, p. 16).

No presente estudo, interessa-nos, de modo especial, a circulação do conhecimento por possibilitar a observação dos saberes e das filiações de sentidos que se estabelecem em dada conjuntura e condições de produção. Pelo modo de circulação, compreendemos, como menciona Orlandi (2005), os trajetos dos dizeres, os quais são igualmente carregados de sentidos, já que “[...] os sentidos são como se constituem, como se formulam e como circulam" (ORLANDI, 2005, p. 12).

Tratar da circulação do conhecimento torna-se fundamental para pensarmos a sua legitimação, pois, a partir do que está posto em circulação, podemos explicitar quais saberes podem e devem ser ditos em determinadas condições de produção. Para Guimarães (2009), o modo de circulação do conhecimento está vinculado a uma determinada política científica, a qual afeta o direcionamento da prática científica de dada conjuntura. O autor enfatiza que

Falar de política científica é falar de algum tipo de controle do que se deve ou não pesquisar. Ou, dito de forma talvez mais branda, do que é mais necessário pesquisar. Assim, falar de política científica é colocar em cena uma discussão sobre a independência da ciência e do cientista. Ou, em outros termos, o que pode ser tomado como elemento que conforma a ação do cientista. (GUIMARÃES, 2009, p. 8).

O modo de circulação do conhecimento contribui, dessa forma, para compreender como um domínio de saber institucionaliza-se por meio dos 'trajetos dos dizeres'. Já a questão institucional, além de particularizar a produção do conhecimento e sua circulação, tem, igualmente, um efeito legitimador, já que são pelas relações institucionais que determinados saberes são legitimados e colocados em circulação. Assim, é conforme as condições sócio-históricas e ideológicas que certos saberes e sentidos são institucionalizados (SCHNEIDERS, 2014).

Nesse viés, consideramos a circulação do conhecimento, em especial em revistas científicas, essencial para observar as filiações de sentidos que se estabelecem em determinadas condições sócio-históricas, visto que, quando certos saberes passam a constituir as práticas científicas, compreendemos uma (de)marcação de lugar em certas condições de produção. Segundo Crespo e Caregnato (2004, p. 2), o “[...] processo de tornar pública uma pesquisa, através de sua publicação, é indispensável para que ela seja legitimada. Isto é identificado como um dos elementos que compõe a base da comunicação científica”.

Para nós, ao tratarmos de revistas científicas, a circulação do conhecimento relaciona-se à ideia de comunicação científica, expressão comumente utilizada pelos estudiosos vinculados à perspectiva da comunicação e informação. Assim, partindo da relação entre circulação e legitimação, a qual, por sua vez, instaura as filiações de sentidos, entendemos que são, sobretudo, essas filiações que permitem aos saberes se institucionalizarem e circularem em dada conjuntura sócio-histórica e ideológica. No entanto, é preciso considerar que a legitimação e/ou institucionalização configura-se através do reconhecimento entre seus pares; ou seja, constitui-se quando determinada prática científica está sujeita ao que Auroux (2008, p. 130) denomina de 'comunidades de conhecimento', cuja função é validar e legitimar os conhecimentos (SCHNEIDERS, 2014).

Schneiders | A circulação do conhecimento linguístico na Revista Brasileira de Filologia 
A respeito da importância dessas comunidades para a prática científica, Santos (1989) destaca que “[...] as condições teóricas do trabalho científico [...] não só evoluem historicamente como a sua aceitação e modo de aplicação num certo momento depende do grupo de cientistas com mais autoridade no seio da comunidade científica" (SANTOS, 1989, p. 139). Para o autor, a comunidade científica é organizada por 'normas sociais' que atuam sobre a produção do conhecimento, instaurando uma forma de 'controle social" interno à comunidade científica. Esta tem, portanto, o papel de fazer a "[...] mediação entre o conhecimento científico e a sociedade no seu todo e na sua tripla identidade sócio-econômica, jurídico-política e ideológica-cultural” (SANTOS, 1989, p. 145).

A comunidade científica tem, pois, como principal função reconhecer os esforços individuais dos membros das próprias comunidades científicas. O reconhecimento coletivo é essencial tanto para o que se coloca em circulação quanto para a produção dos conhecimentos, além de possibilitar a troca contínua de informações com seus pares, contribuindo para a configuração do que entendemos como horizonte de retrospecção e horizonte de projeção (AUROUX, 1992, 2008).

Partindo dessas questões que se vinculam à circulação do conhecimento e à comunicação científica, em especial, de revistas científicas, buscamos, na sequência, observar o funcionamento discursivo da RBF. Para tanto, destacaremos alguns aspectos referentes à estrutura e à organização interna da revista, a fim de compreender como as revistas científicas contribuem para a constituição e legitimação de determinados domínios de saber.

\section{SOBRE A REVISTA BRASILEIRA DE FILOLOGIA}

A RBF foi criada em 1955, no Rio de Janeiro, por Serafim da Silva Neto, que passou também a dirigi-la. A RBF logo se tornou “[...] a mais completa e categorizada publicação do gênero no país" (ELIA, 1975, p. 158). Trata-se de uma revista representativa do período que envolve os anos de 1950 e 1960, como bem destaca Castilho (1962).

A RBF era publicada pela Livraria Acadêmica, do Rio de Janeiro, editora na qual se publicaram muitas das obras filológicas no período, inclusive de Silva Neto. A revista tinha uma periodicidade semestral, com a publicação de um volume por ano, sendo que o mesmo era composto por dois tomos, um por semestre. A RBF teve seis volumes, totalizando a publicação de onze tomos faltando somente o tomo II, do volume 6. Serafim da Silva Neto, além de fundar, dirigiu a RBF até o ano de 1958, quando da publicação do volume 4. Os dois últimos volumes foram dirigidos pela comissão formada por Antenor Nascentes, Ismael de Lima Coutinho, Sílvio Elia e Mattoso Câmara. No entanto, com a morte de seu fundador, em 1960, a revista passou a ter menos regularidade e foi publicada somente até 1961.

A relevância da RBF, para a época, é devido ao olhar diferenciado que lançava sobre os estudos em torno da Língua Portuguesa do Brasil, procurando fazer com que os estudos de Filologia Românica progredissem. Em seu primeiro volume, tomo 1, no "A guisa do prólogo", escrito pelo fundador da revista, Serafim da Silva Neto, verificamos os objetivos propostos para a RBF:

A Revista Brasileira de Filologia deseja contribuir para o desenvolvimento dos estudos científicos da Língua Portuguêsa, encarada, naturalmente, no grupo das línguas românicas e nas suas relações com as demais Ciências do Homem. É sua intenção tratar de todos os pontos relativos a uma das línguas mais faladas do mundo provavelmente meio de expressão de para além de setenta milhões de almas.

Pretende ainda ser um elo a mais a prender Portugal e Brasil na investigação de um bem que lhes é hoje propriedade comum: deseja constituir um modesto, mas fraternal ponto de encontro entre os filólogos d'aquém e d'além mar.

Apesar do interêsse, que já frisamos, por todos os assuntos relativos à língua portuguêsa, sem qualquer restrição geográfica, a nossa revista pretende dar atenção especial ao português do Brasil. (REVISTA BRASILEIRA DE FILOLOGIA, 1955, p. 1). 
Elia (1975, p.158) salienta que a RBF: "[...] de número para número vinha cumprindo o programa que se impusera. A Revista Brasileira de Filologia, como já tivemos a oportunidade de dizer, foi à época a melhor publicação do gênero. Altos louvores mereceria a Livraria Acadêmica se se decidisse continuar a sua publicação, no mesmo nível a que se elevara o prof. Serafim da Silva Neto”.

No estudo empreendido por Coseriu (1976 [1968]) sobre o desenvolvimento da Linguística latino-americana, a RBF é considerada como o principal periódico linguístico-histórico do Brasil. Para o autor, tal periódico, se comparado aos demais periódicos do contexto latino-americano, vinculava-se mais a discussões referentes à Linguística, especialmente à Linguística Histórica, do que à Filologia, dedicando também um grande espaço ao estruturalismo.

Considerando a estrutura da RBF, observamos que, de um modo geral, ela é composta da seguinte forma: primeiramente, verificamse artigos de diferentes e importantes estudiosos que tratam de questões da língua por meio de um viés histórico e filológico. Na sequência, é dedicada uma seção denominada "Crônica Linguística”, cujo responsável é Joaquim Mattoso Câmara Jr. Após, há um espaço destinado a "Recensões Críticas e Notas Bibliográficas", a fim de divulgar estudos realizados a partir de um olhar crítico, no caso das "recensões críticas", e de apresentar pontos relevantes sobre bibliografias recém-publicadas, como é o caso das "notas bibliográficas". Nessa parte, observamos o comparecimento de estudos tanto do domínio da Linguística quanto da Filologia, ou seja, o interesse é divulgar/fazer circular os estudos realizados sobre a língua/linguagem.

A parte final da composição da RBF é dedicada a "notícias e comentários" sobre eventos, reuniões, cursos etc., realizados à época. Ainda, alguns tomos da revista finalizam com uma seção denominada "In memoriam", com vistas a homenagear estudiosos que foram essenciais para o desenvolvimento das pesquisas linguísticas no Brasil.

Cabe pontuar que a estrutura e a organização dessa revista tiveram como molde a Revista Portuguesa de Filologia, dirigida por Manuel de Paiva Boléo, da Universidade de Coimbra. Entendemos que essa proximidade entre as duas revistas deve-se à relação acadêmica que existia entre Serafim da Silva Neto e Manoel de Paiva Boléo, um importante filólogo português.

Tendo em vista a importância da RBF, passaremos a apresentar alguns possíveis movimentos analíticos, com vistas a observar o funcionamento da constituição dessa materialidade. Diante do nosso objetivo, que é compreender a contribuição da RBF tanto para a circulação como para a constituição dos saberes linguísticos, considerando especialmente a contribuição dessa revista científica para o contexto do sul do Brasil, partimos dos seguintes 'modos de entrada' para adentrar na materialidade discursiva: 1) análise do sumário, para observar quais estudiosos publicam nessa revista; 2) análise das "Crônicas linguísticas", as quais tinham como responsável Mattoso Câmara Jr., estudioso de grande importância para a disciplinarização da Linguística no Brasil; 3) análise das "Notícias e comentários", espaço onde podemos verificar a difusão e circulação do conhecimento linguístico no Brasil, enfatizando, sobretudo, as questões que dizem respeito ao sul do Brasil.

Embora consideremos, para fins analíticos, esses modos de entrada em específico, também atentaremos para algumas das variáveis propostas por Chevalier (1998), em seu estudo sobre o lugar das revistas na constituição de uma disciplina, retomadas também por Scherer (2003), em seu estudo acerca da revista Trabalhos em Linguística Aplicada. Segundo Chevalier (1998), para analisar a dinâmica do desenvolvimento científico, tomando como objeto as revistas, deve-se considerar a especificidade própria de cada uma. O autor elenca alguns aspectos ou variáveis que podem ser produtivos quando analisamos o funcionamento dessa materialidade. Desse modo, retomaremos cada um deles, relacionando-os com o que nos apresenta a RBF.

O primeiro aspecto proposto por Chevalier (1998) diz respeito ao título da revista, o qual visa a fixar/delimitar o(s) domínio(s) que serão postos em circulação pela revista. No caso da RBF, como já adiantamos anteriormente, trata-se de uma revista científica dita especializada, uma vez que seu título, Revista Brasileira de Filologia, especifica o domínio de saber a que se filia: 'Filologia'. No entanto, ao verificarmos a presença da seção "Crônica linguística”, na constituição de uma revista de Filologia, observamos que, mesmo o título indicando a especialidade da revista, esta pode estar composta por outros domínios de saber. Assim, podemos dizer que o título tem por função atingir um público alvo, evocando ambições midiáticas, como ressalta Chevalier (1998). 
O segundo aspecto é referente ao comitê editorial, ou dos diretores da revista. Para Chevalier (1998), os nomes presentes nesse(s) comitê(s) deveriam definir o campo científico, contudo, devemos olhar para esse aspecto com algumas ressalvas, pois as lutas pelo poder podem aí estar mascaradas. Na RBF, verificamos apenas a presença, na contracapa, do nome de um diretor, que foi também o fundador dessa revista científica: Serafim da Silva Neto. Como sabemos, após o volume 4, uma comissão foi formada para dirigila; porém, essa comissão não consta explicitada nos volumes que organizaram.

O terceiro aspecto que pode ser observado é a editora ou o lugar de edição. Chevalier (1998) propõe que se poderiam considerar duas soluções quando pensamos o lugar de edição de uma revista: a primeira e, geralmente, a única, no entender do autor, seria as Editoras universitárias. Como a publicação das revistas científicas não visa ao lucro, elas mesmas acabam vinculando-se a Universidades ou a Associações, o que, muitas vezes, faz com que elas estejam expostas a jogos de força pelo poder.

A outra solução apontada por Chevalier (1998) são os editores privados, solução referente ao quarto aspecto levantado pelo autor ao analisarmos revistas. Quando se opta por editores privados, as revistas devem se inscrever na política adotada pela editora. A RBF, como já sinalizamos, é publicada pela Livraria Acadêmica, a qual teve um papel fundamental no que tange à difusão do conhecimento, pois era por meio dela que os estudiosos tinham acesso, em especial, às obras estrangeiras, além de terem a possibilidade de publicar seus estudos.

Passando para o quinto aspecto destacado por Chevalier (1998), sobre os meios de comunicação, ressaltamos a questão das línguas presentes na revista. Para o autor, a escolha das línguas é determinante, por ampliar, de certa forma, o público visado. Na RBF, temos a presença de artigos em Língua Espanhola e Língua Francesa, ou seja, embora a revista seja monolíngue, escrita em Língua Portuguesa, há a inserção de outras línguas devido à publicação de artigos de estudiosos de outros países. Entendemos que a preservação dos artigos em sua versão original deve-se ao fato de tratarmos de uma conjuntura onde o público-alvo tinha o domínio de diversas línguas, bem como ao fato de possibilitar a circulação da revista fora do âmbito nacional.

O sexto aspecto diz respeito à importância de considerar se as revistas são editadas por um grupo de trabalhos, permitindo, a partir de uma base teórica comum, a publicação de artigos distintos que correspondem a diversas áreas de pesquisa. Segundo Chevalier (1998), a publicação de números mais diversificados e não temáticos, que restringiria a circulação da revista, possibilita abranger um público mais amplo. Tendo em vista a estrutura da RBF, detalhada anteriormente, podemos dizer que ela se enquadra em um número diversificado, já que não verificamos uma delimitação/especificação da temática para cada tomo publicado, isto é, busca-se enfatizar estudos que tratam da língua/linguagem através de diferentes enfoques.

O sétimo aspecto que Chevalier (1998) ressalta é sobre a evolução da ciência, os movimentos das pesquisas, que são fundamentais para a criação/modificação das revistas, ligadas, por sua vez, ao desenvolvimento de grupos institucionais. Para nós, esse aspecto se torna relevante na medida em que a fundação/publicação da RBF insere-se em uma conjuntura bastante profícua para o desenvolvimento dos estudos linguísticos e a sua constituição interna reflete, de certo modo, os domínios de saber que estavam em circulação à época, questão essa que observaremos com os recortes discursivos analisados.

O oitavo e último ponto enfatizado por Chevalier (1998) é sobre a questão das relações estabelecidas com a comunidade, o que, para ele, é difícil de determinar. Devido a essa dificuldade, entendemos e propomos que uma possibilidade de se observar as relações com a comunidade, ou melhor, com a comunidade científica, seria partir da relação, ou não, institucional entre os estudiosos que publicam em determinada revista científica. Nesse ponto, não especificaremos o caso da RBF, uma vez que demandaria uma análise exaustiva, retomando todos os estudiosos que estão presentes, com publicações, nos volumes da revista.

Diante da complexidade que envolve a análise do funcionamento discursivo das revistas científicas, essas variáveis ou aspectos levantados por Chevalier (1998) tornam-se importantes princípios metodológicos, contribuindo para adentrarmos na materialidade discursiva das revistas. Assim, a seguir, procuramos lançar gestos de interpretação sobre a discursividade em análise, partindo dos três modos de entrada já especificados. 


\section{A REVISTA BRASILEIRA DE FILOLOGIA E O SEU FUNCIONAMENTO DISCURSIVO}

No estudo empreendido, procuramos, portanto, compreender a contribuição da RBF tanto para a circulação como para a constituição dos saberes linguísticos, interessando-nos, de modo especial, a contribuição dessa revista científica para o contexto do sul do Brasil. Para explicitarmos esse funcionamento discursivamente, mobilizamos, como objeto de análise, todos os tomos/volumes publicados da revista, a partir dos quais pudemos verificar regularidades que nos permitiram estabelecer os 'modos de entrada' utilizados para analisar essa materialidade. Primeiramente, apresentaremos o que observamos em cada modo de entrada, para, após, lançarmos gestos de interpretação sobre a materialidade em questão.

Ao analisarmos o sumário das revistas - primeiro modo de entrada - estabelecemos os outros modos de entrada, pois, além de apontar para os estudiosos que publicam, o sumário explicita a organização interna da revista. Como nosso olhar volta-se, em especial, para a contribuição da RBF para o contexto do sul do Brasil, destacamos apenas os estudiosos do contexto sul-riograndense que comparecem na revista. Os estudiosos que verificamos foram os seguintes:

\footnotetext{
* Albino de Bem Veiga, com o artigo: "Virgeu de Consolaçon” (REVISTA BRASILEIRA DE FILOLOGIA, 1956b, p. 217).

* Dante de Laytano, com o artigo: "Fontes escritas para o conhecimento dos falares do Rio Grande do Sul” (REVISTA BRASILEIRA DE FILOLOGIA, 1957a, p. 129).

* Celso Pedro Luft, com o artigo: “Tratamento depreciativo” (REVISTA BRASILEIRA DE FILOLOGIA, 1957b, p. 193).
}

Com relação à seção das crônicas linguísticas, todas de autoria de Mattoso Câmara Jr., verificamos que nem todos os tomos e volumes possuem essa seção, as que constatamos foram:

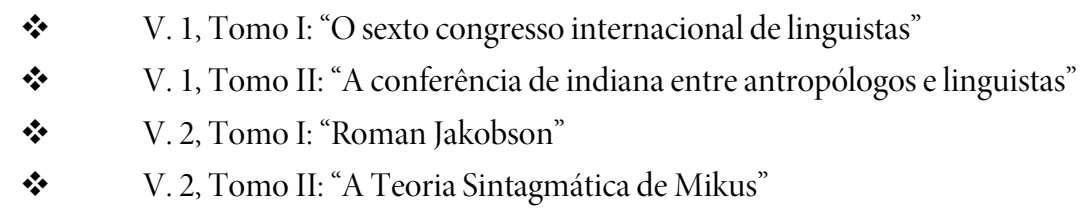

A primeira crônica traz um interessante panorama das “Atas do Sexto Congresso Internacional de Linguistas”, realizado em Paris, em 1948. As atas, segundo Mattoso Câmara Jr., "[...] permitem uma boa visão das correntes e tendências da linguística contemporânea, apesar da ausência de algumas figuras individuais de relevo e da de certos grupos nacionais, que por contingências da situação do mundo não tiveram representação no Congresso” ( REVISTA BRASILEIRA DE FILOLOGIA, 1955, p. 53). Tal crônica se faz relevante por colocar em circulação as discussões sobre a Linguística que se vinham realizando, bem como o fato de referenciar importantes nomes desse domínio de saber ${ }^{2}$.

Na segunda crônica, "A Conferência de Indiana entre Antropólogos e Linguistas", verificamos um breve relato sobre essa conferência, enfatizando, sobretudo, a relação entre a linguística e a antropologia cultural. Essa conferência foi realizada em julho de 1953, e Mattoso Câmara Jr. atenta para o fato de que a crônica não traz um relato do todo, omitindo alguns temas e debates “[...] em detrimento de umas poucas idéias, aí ventiladas, que pareceram especialmente significativas [...] para os brasileiros" (REVISTA BRASILEIRA DE FILOLOGIA, 1955, p. 195).

Podemos dizer que a ênfase dada por Mattoso Câmara Jr. na relação entre a Linguística e a Antropologia nessa crônica não se dá por acaso. Consideramos isso pelo fato de Mattoso, nos anos de 1940, trabalhar voluntariamente no Museu Nacional, onde manteve

\footnotetext{
${ }^{2}$ Não realizaremos uma descrição minuciosa de cada crônica, interessa-nos apenas destacar o que se veicula em cada crônica para refletirmos sobre seu funcionamento, tendo em vista que tratamos de uma revista de Filologia.
} 
contato com antropólogos. Esse contato possibilitou que viajasse para os Estados Unidos (1943-1944) e se relacionasse teoricamente com Roman Jakobson e Louis Gray (GUIMARÃES, 2004; ORLANDI, 2002a).

A terceira crônica diz respeito à "Roman Jakobson”, em comemoração aos seus sessenta anos. Nessa crônica, Mattoso Câmara Jr. traz uma síntese da “[...] figura e da obra de Roman Jakobson nos quadros da linguística contemporânea”, além de destacar o vínculo do pensamento científico deste estudioso com o de Troubetzkoy. As crônicas da RBF, tal como observamos nas duas primeiras, estavam destinadas a registrar eventos “[...] significativos na linguística internacional”, porém, nesta, como justifica Mattoso, "[...] é justo que se aproveitem tôdas as oportunidades de ressaltar as contribuições, para a consolidação, aprimoramento e renovação da ciência da linguagem, trazidas, por linguistas do nosso tempo entre os quais aquêle de quem tratamos, é sem sombra de contestação um dos mais valiosos" (REVISTA BRASILEIRA DE FILOLOGIA, 1956a, p. 55).

Em nota de rodapé e a título de curiosidade, o autor destaca uma interessante informação: a possibilidade de Jakobson ter vindo para o Brasil, por convite da Universidade de São Paulo, antes de ter ido para os Estados Unidos. No entanto, isso não se efetivou “[... em virtude de empecilhos ulteriores”, nas palavras de Mattoso Câmara Jr.

E a quarta e última crônica linguística: "A Teoria Sintagmática de Mikus", discute a questão do sintagma, retomando, primeiramente, os pressupostos saussurianos, para, em seguida, trazer o estudo desenvolvido por Francis Mikus acerca dessa temática. Essa crônica, assim como a anterior, não apresenta o registro de eventos, mas uma questão teórica sob o ponto de vista da linguística moderna.

O último modo de entrada estabelecido foi a observação da seção "Notícias e comentários", por se tratar de um espaço onde verificamos a difusão e a circulação do conhecimento linguístico no Brasil, e, em especial, onde observamos questões referentes ao sul do Brasil. Selecionamos quatro recortes discursivos dessa seção, os quais dizem respeito aos eventos realizados ou que se realizariam no ano corrente da referida publicação. Para nós, que nos situamos no domínio da História das Ideias Linguísticas, tais acontecimentos não são observados cronologicamente, mas sim na sua relação com a exterioridade, "circunstanciados a certas condições (científicas, políticas, sociais, históricas, etc.)" (ORLANDI, 2002b, p. 41).

Nesse sentido, entendemos que tanto as crônicas linguísticas, seja para relatar os congressos seja para destacar estudiosos/estudos relevantes, como a seção de notícias e comentários permitem-nos refletir sobre a constituição e circulação das ideias linguísticas em determinada conjuntura sócio-histórica e ideológica. Sobre a importância dos eventos (incluindo aí os congressos, associações, etc.) para a História das Ideias Linguísticas, podemos nos reportar ao estudo realizado por Orlandi (2002b), intitulado: "Ir ao congresso: fazer a história das ideias linguísticas?", o qual explicita o papel fundamental que esses acontecimentos possuem para o desenvolvimento do conhecimento linguístico.

Tendo isso em vista, passamos aos recortes discursivos realizados da seção "Notícias e comentários":

UNIVERSIDADE DO RIO GRANDE DO SUL

No mês de maio de 1954, Serafim da Silva Neto foi Professor visitante na Faculdade de Filosofia, onde deu um Curso de Extensão na Cadeira de Português regida pelo Prof. Albino de Bem Veiga. É a seguinte a súmula das aulas, às quais compareceram mais de cem professôres e alunos:

Recorte 1

Fonte: REVISTA BRASILEIRA DE FILOLOGIA (1955, p. 103).

Resumidamente, a súmula das aulas ministradas por Serafim da Silva Neto teve as seguintes temáticas:

1- CONSTITUIÇÃO DA FILOLOGIA PORTUGUÊSA

2- O CHAMADO LATIM VULGAR

3- $\quad$ ORIGEM E FORMAÇÃO DA LÍNGUA PORTUGUÊSA

Forum linguistic., Florianópolis, v.14, n.4,p. 2756-2770, out./dez. 2017. 


\section{CENTRO DE ESTUDOS FILOLÓGICOS DA FACULDADE CATARINENSE DE FILOSOFIA}

Na primeira quinzena de Outubro, realizou, a Faculdade de Filosofia e a concite de seu Diretor, o Senhor Desembargador Henrique da Silva Fontes, um curso de extensão universitária sobre Filologia Portuguêsa e um curso de Dialectologia Brasileira o Professor Catedrático de Filologia Românica da Pontifícia Católica do Rio de Janeiro Serafim da Silva Neto.

Realizando a par das exposições teóricas, trabalhos práticos de dialectologia, foi objetivo do Prof. Serafim da Silva Neto não só informar todos os que estiveram interessados no assunto do que de mais recente e de melhor quilate científico se tem realizado nos campos da filologia e da dialectologia, como também preparar uma turma de pesquisadores que tomem sôbre si a tarefa de levantamento dialectológico do Estado.

As aulas do Professor Serafim da Silva Neto realizaram-se na Faculdade de Filosofia, de manhã eà tarde, tendo frequentado os cursos professores de ensino primário, secundário e superior, alunos de Faculdades, folcloristas, etnógrafos e, de um modo geral, todos os interessados em filologia e dialectologia. No curso livre de Dialectologia Brasileira foram entregues diplomas de freqüência a todos àqueles que assistiram a, pelo menos, dois terços as aulas dadas.

Recorte 2

Fonte: REVISTA BRASILEIRA DE FILOLOGIA (1956a, p. 137).

Após um relato dos cursos realizados, verificamos o programa do curso de Dialetologia:

I - Importância da Dialectologia. Histórico;

II - Conceito de dialecto e de falar: necessidade e urgência do seu estudo;

III - A Dialectologia Portuguêsa. Bibliografia;

IV - A estrutura lingüística;

V - A Dialectologia Brasileira: apreciação dos trabalhos empreendidos até agora;

VI - A moderna técnica de investigação dialectal. O questionário e o inquérito;

VII - Os Atlas Lingüísticos: o que são e para o que servem;

VIII - Interpretação dialectal de Santa Catarina: problemas que suscita, sugestão de trabalhos e programas de estudos.

\section{UNIVERSIDADE DO RIO GRANDE DO SUL}

A convite da Faculdade de Filosofia, realizou-se de 1 a 15 de agôsto p.p., um Curso de Dialectologia destinado a preparar o ambiente para um futuro Congresso de Dialectologia Brasileira a realizar-se em Pôrto Alegre. As aulas, que foram ministradas pelo Prof. Serafim da Silva Neto, obedeceram ao seguinte plano:

- Língua comum, dialetos e falares.

- O inquérito lingüístico. Suas técnicas.

- Os atlas lingüísticos: o que são e para o que servem.

- Atlas e dicionários regionais.

- Os problemas do questionário.

Foi escolhida uma Comissão, constituída dos Professôres Elpídio Pais, Albino de Bem Veiga, Heinrich Bunse e Celso Pedro Luft, para elaborar um projeto de questionário lingüístico destinado ao futuro Atlas do Sul do Brasil. 


\section{I. ${ }^{\circ}$ CONGRESSO BRASILEIRO DE ETNOGRAFIA E DIALECTOLOGIA}

$\mathrm{Na}$ Faculdade de Filosofia da Universidade de Pôrto Alegre realizou-se, de 1 a 7 de setembro, o I ${ }^{\circ}$ Congresso Brasileiro de Etnografia e Dialectologia que teve a participação de numerosos Professores brasileiros e alguns mestres de fora, como Eugênio Asensio, I. S. Révah, Luís Filipe Lindley Cintra, José Herculano de Carvalho, Manuel Alvar, Eugênio Coseriu, José Pedro Rona, J. M. Piel e Diego Catalan. Dirigiu o Congresso, como Presidente Executivo, o Professor Albino de Bem Veiga, Catedrático de Filologia Portuguêsa da Universidade do Rio Grande do Sul.

Recorte 4

Fonte: REVISTA BRASILEIRA DE FILOLOGIA (1958, p. 288-289).

A partir dos modos de entrada destacados, observamos a maneira como a RBF contribui para a constituição e circulação do conhecimento linguístico, tanto no âmbito nacional como no âmbito do sul do Brasil. Para nós, as revistas científicas, enquanto objetos de estudo, podem ser consideradas essenciais para se analisar a dinâmica do desenvolvimento científico.

Entendemos que os três modos de entrada são complementares, uma vez que possibilitam estabelecer relações entre quem publica, os saberes linguísticos veiculados e a legitimação/constituição de determinados domínios de saber. Assim, retomar os estudiosos, pertencentes ao contexto sul-rio-grandense, que publicaram na RBF, é fundamental para refletirmos sobre as relações institucionais estabelecidas entre a comunidade científica da época, as quais são, de certo modo, corroboradas/reforçadas na seção "Notícias e comentários", por tais estudiosos se fazerem presentes novamente.

No que se refere à constituição e circulação do conhecimento linguístico, as "Crônicas linguísticas" e as "Notícias e Comentários" configuram-se como importantes 'entradas' para tratar desse ponto. Pelas crônicas, todas de autoria de Mattoso Câmara Jr., e pelo fato de ser esse estudioso quem buscou introduzir os preceitos da Linguística Estrutural no Brasil, entendemos que a RBF, mesmo sendo uma revista científica de Filologia, contribui não só para a circulação dos saberes do domínio da Linguística, como também para a legitimação/constituição desse domínio de saber no contexto brasileiro, visto que, à época, tratava-se de um campo ainda não disciplinarizado no âmbito acadêmico e, muitas vezes, não ‘bem visto’ por alguns filólogos, grupo de especialidade predominante nessa conjuntura.

É interessante observar também que, embora Mattoso Câmara Jr. tenha tido um lugar periférico junto aos seus pares e em sua carreira acadêmica, pelo fato de filiar-se ao domínio da Linguística, vemos, pela RBF, que “[...] seus textos eram acolhidos em [...] periódicos em que também publicavam os filólogos. Portanto, se a sua posição no grupo não foi das mais destacadas, não foi também o que se pode chamar com exatidão de 'marginal”' (COELHO, 1998, p. 101).

Ainda sobre as crônicas, especialmente as que se referem à divulgação dos congressos internacionais de linguística, podemos dizer, a partir do que destaca Orlandi (2002b) sobre essa questão dos congressos, que Mattoso,

Sem se colocar no interior da história da linguística ao falar de seus congressos, vai colocando aos poucos nossa história como menção, quase casual. Isso me leva a dizer que ele se coloca na posição de quem é lingüista, de quem, com outros, daqui e de "lá" faz essa história, mas não afirma sua posição como "participante", do ponto de vista dos Congressos. Ele está, com isso, preparando a vinda dos congressos brasileiros, nossa visibilidade como lingüistas. (ORLANDI, 2002b, p. 52).

Desse modo, as crônicas linguísticas da RBF nos permitem compreender que, mesmo sendo uma revista científica dita especializada, em sua constituição, há a presença de outros domínios de saber, como é o caso da Linguística, contribuindo, portanto, para a circulação e, de certa forma, para a institucionalização desse domínio no contexto brasileiro. Nesse viés, vincula-se também a seção das 'notícias e comentários', no entanto, contribuindo para refletirmos sobre a circulação e constituição da Dialetologia.

O primeiro recorte dessa seção trata-se da notícia sobre o Curso de Extensão, realizado por Serafim da Silva Neto, em 1954, na UFRGS, na Cadeira de Português regida pelo Prof. Albino de Bem Veiga. Tal curso, conforme a súmula das aulas, enfatizou,

Forum linguistic., Florianópolis, v.14,n.4,p. 2756-2770, out./dez. 2017 
sobretudo, os estudos filológicos. É interessante considerar essa notícia para refletirmos sobre as filiações teóricas/relações institucionais estabelecidas entre o contexto sul-rio-grandense e o contexto nacional, as quais se evidenciam pelos nomes dos dois estudiosos que comparecem na notícia ${ }^{3}$.

Nos é pertinente a questão da filiação, pois, como assinala Orlandi (2002a, p. 156), "quando os autores se filiam a uma teoria e não outra, e quando fazem um recorte do objeto de conhecimento, estão produzindo uma política de ciência com conseqüências para uma política social". Ao inscrever-se num domínio de saber, o sujeito, ao mesmo tempo, filia-se a ele e aos sentidos colocados em funcionamento pela determinação histórica.

Para Lagazzi-Rodrigues (2007), "filiar-se a uma teoria é reconhecer-se frente a determinadas possibilidades de perguntas e de práticas científicas, em determinadas condições de produção" (p. 13). Por meio da relação com os saberes que formam o campo do conhecimento a que se filia, o sujeito configura sua prática científica, a qual passa a circular, em determinadas condições, especialmente quando reconhecida e legitimada (cf. SCHNEIDERS, 2014).

Com relação aos outros recortes, todos dizem respeito aos cursos realizados sobre o domínio da Dialetologia entre os anos de 1956 e 1958. Essa constante divulgação de eventos/cursos de Dialetologia vincula-se ao fato de, na época, ter um movimento em favor desse campo de estudo, cujo principal nome foi o de Serafim da Silva Neto. Este, nos anos de 1950, em busca de garantir um espaço institucional e implantar uma 'mentalidade dialetológica' no Brasil, fundou, em 1953, o Centro de Estudos de Dialetologia Brasileira, no Museu Nacional do Rio de Janeiro, e procurou difundir a dialetologia brasileira através de palestras por todo o Brasil, inclusive no Sul, como observamos pelos recortes da seção 'notícias e comentários'.

No segundo recorte, em específico, observamos a presença de dois cursos realizados na Faculdade Catarinense de Filosofia, em 1956: um de Filologia e outro de Dialetologia. Chamamos a atenção para esse fato, uma vez que, inicialmente, a Dialetologia, enquanto programa que buscava dados a respeito das diferentes variantes regionais do português do Brasil, foi incorporada ao programa de Filologia, o que lhe garantia legitimidade, por ser o domínio de saber dominante da época (ALTMAN, 2004).

Já o terceiro e quarto recortes noticiam a realização de um curso e de um Congresso de Dialetologia, respectivamente. No recorte referente ao Curso de Dialetologia Brasileira realizado na Faculdade de Filosofia da UFRGS, em 1957, observamos a ênfase em 'preparar o ambiente para o futuro Congresso de Dialetologia Brasileira', e, segundo o plano das aulas, verificamos que se busca apresentar 'as tarefas' da Dialetologia, ou seja, apresentar o programa desse domínio de saber. A divulgação desse campo de estudo e de seu programa, por meio de cursos e congressos, foi fundamental para o seu estabelecimento e legitimação, fazendo com que houvesse uma crescente preocupação na elaboração e publicação de Atlas Linguísticos e de Guias Dialetológicos (ALTMAN, 2004).

O quarto recorte, sobre o I Congresso Brasileiro de Etnografia e Dialectologia, já mencionado no terceiro recorte, foi mobilizado pelo fato de explicitar os estudiosos brasileiros e estrangeiros que participaram desse congresso, em 1958, na UFRGS. Esses nomes marcam, portanto, a relação existente entre um grupo de estudiosos a partir de um interesse em comum: os estudos dialetológicos. Dentre esses estudiosos, chamamos a atenção, em especial, para a presença de Eugênio Coseriu, uma vez que é uma referência constante, com a publicação de artigos, nos tomos da RBF.

No respeitante à década de 1950, como bem nos explicitam os recortes, observamos uma crescente divulgação dos estudos da Dialetologia via cursos e congressos, apontando para o que Altman denomina de a "década da renovada cruzada dialetológica de Silva Neto" (2004, p. 80). Desse modo, podemos dizer que os acontecimentos exteriores, mais precisamente os movimentos científicos, afetam/determinam a constituição e o funcionamento da materialidade discursiva analisada.

\footnotetext{
${ }^{3}$ Essa relação institucional entre Serafim da Silva Neto e Albino de Bem Veiga também está marcada na Revista Organon, onde verificamos, no primeiro número publicado, a presença de um artigo de Serafim da Silva Neto, bem como uma apresentação desse estudioso, escrita por Albino de Bem Veiga, com menção ao curso que realizou. Um estudo sobre essa revista foi realizado Scherer e Petri (2015).
} 


\section{PALAVRAS FINAIS}

Nessa reflexão, buscamos, portanto, compreender a maneira como a RBF contribui para a constituição e circulação do conhecimento linguístico tanto no contexto nacional como no sul do Brasil. Pelos modos de entrada estabelecidos, consideramos que a materialidade tomada como objeto de análise pode ser considerada como um espaço discursivo privilegiado, que nos possibilita observar os estudos que envolvem a prática científica desenvolvida nos anos de 1950. Em se tratando especificamente do contexto sul-rio-grandense, a RBF permite-nos, igualmente, explicitar quais saberes linguísticos estão em circulação nessa conjuntura só-histórica e ideológica, bem como estabelecer possíveis filiações teóricas entre esse contexto e um dos principais centros de estudos da época, situado no Rio de Janeiro.

Logo, quando analisamos o funcionamento discursivo de revistas científicas, como Chevalier (1998) destaca, podemos entender a dinâmica do desenvolvimento científico, o qual se configura a partir de condições sócio-históricas e ideológicas específicas. A produção de conhecimento, como enfatiza Scherer (2008), é, portanto, "[...] um trabalho permanente de demarcação de lugar, trabalho que envolve um policiamento incessante de fronteiras e uma vigilância epistemológica ímpar de domínios, a fim de que possamos manter as rédeas de nossa sujeição nos possíveis deslizamentos de sentido na constituição do campo de saber em que estamos postos." (SCHERER, 2008, p. 133).

Pelas considerações realizadas, pontuamos que, além de permitir compreender a dinâmica do desenvolvimento científico, a Revista Brasileira de Filologia contribui de modo especial para refletirmos sobre a constituição das ideias linguísticas tanto no sul como no contexto nacional. Essa constituição, no entanto, só pode ser estabelecida devido ao olhar retrospectivo que lançamos sobre a materialidade em estudo. Assim, para finalizar, retomamos uma citação de Serafim da Silva Neto que resume, de certa forma, o papel que a RBF e os estudiosos tiveram à época: “[...] são sempre mais felizes os que vêm depois de nós, pois encontram ambiente que preparamos e podem aproveitar-se do nosso trabalho e da nossa experiência” (RBF, v. 4, Tomos I-II, 1958, p. 292).

\section{REFERÊNCIAS}

ALTMAN, C. A pesquisa lingüística no Brasil (1968-1988). 2. ed. São Paulo: Humanitas, 2004.

AUROUX, S. A revolução tecnológica da gramatização. Trad. Eni P. Orlandi. Campinas: UNICAMP, 1992.

. A questão da origem das línguas, seguido de A historicidade das ciências. Trad. Mariângela Pecciolli Gali Joanilho. Campinas: RG, 2008.

BUSCÁCIO, L. Mário de Andrade, um arquivo de saberes sobre a língua do/no Brasil. 2014. 347 f. Tese (Doutorado em Estudos da Linguagem) - Universidade Federal Fluminense, Instituto de Letras, Rio de Janeiro, 2014.

CASTILHO, A. T. de. Estudos lingüísticos no Brasil. Revista Alfa, Araraquara, v. 2, 1962.

CHEVALIER, J.-C. Place des revues dans la constituition d'une discipline: la linguistique française (1945-1997). Langue Française, Paris, n. 117, p. 68-81, 1998.

COELHO, O. F. Serafim da Silva Neto (1917-1960) e a Filologia Brasileira. Um Ensaio Historiográfico sobre o Papel da Liderança na Articulação de um Paradigma em Ciência da Linguagem. 1998. 184f. Dissertação (Mestrado em Letras) - Faculdade de Filosofia, Letras e Ciências Humanas da Universidade de São Paulo, São Paulo, 1998. 
COSERIU, E. Perspectivas gerais. In: NARO, A. J. (Org.). Tendências atuais da lingüística e da filologia no Brasil. Rio de Janeiro: Francisco Alves, 1976 [1968]. p. 11-40.

CRESPO, I. M.; CAREGNATO, S. Periódicos científicos eletrônicos: identificação de características e estudo de três casos na área de comunicação. In: ENCONTRO DE INFORMAÇÃO EM CIÊNCIAS DA COMUNICAÇÃO, 16., 2004. Disponível em: <http://www.portcom.intercom.org.br/institucional/a_rede/endocom/2004/Crespo.PDF.> Acesso em: 28 ago. 2015.

ELIA, S. Ensaios de filologia e lingüística. 2. ed. Rio de Janeiro: Grifos, 1975.

GUIMARÃES, E. História da semântica: sujeito, sentido e gramática no Brasil. Campinas: Pontes, 2004.

Linguagem e conhecimento: Produção e circulação da ciência. Revista Rua (online), Campinas, v. 2, n. 15, p. 5-14, nov. 2009.

LAGAZZI-RODRIGUES, S. O político na Lingüística: Processos de representação, legitimação e institucionalização. In: ORLANDI, E.; GUIMARÃES, E. (Org.). Política lingüística no Brasil. Campinas: Pontes, 2007. p. 11-18.

ORLANDI, E. Língua e conhecimento lingüístico: para uma história das idéias no Brasil. São Paulo: Cortez, 2002a.

Ir ao congresso: fazer a história das idéias linguísticas? In: GUIMARÃES, E; ORLANDI, E. (Org.). Institucionalização dos estudos da linguagem: a disciplinarização das idéias lingüísticas. Campinas: Pontes, 2002b. p. 41-62.

. Discurso e texto: formulação e circulação de sentidos. Campinas: Pontes, 2005.

REVISTA BRASILEIRA DE FILOLOGIA, v. 1, Tomo I, jun. 1955.

,v. 1, Tomo II, dez. 1955.

,v. 2, Tomo I, jun. 1956a.

, v. 2, Tomo II, dez. 1956b.

,v. 3, Tomo I, jun. 1957a.

, v. 3, Tomo II, dez. 1957b.

,v. 4, Tomos I-II, 1958. 
SANTOS, B. S. Introdução a uma ciência pós-moderna. Rio de Janeiro: Ed. Graal, 1989.

SCHERER, A. E. A história e a memória na constituição do discurso da linguística aplicada no Brasil. In: CORACINI, M. J.; BERTOLDO, E. S (Org.). O desejo da teoria e a contingência da prática: discursos sobre e na sala de aula. Campinas: Mercado de Letras, 2003. p. 61-82.

. Dos domínios e das fronteiras: o lugar fora do lugar em outro e mesmo lugar. In: SARGENTINI, V.; GREGOLIN, M. do R. (Org.) Análise do Discurso: heranças, métodos e objetos. São Carlos: ClaraLuz, 2008. p. 131-141.

SCHERER, A. E; PETRI, V. ORGANON: entre a história e a memória no institucional acadêmico-científico do Sul do Brasil, Organon, Porto Alegre, v. 30, n. 59, p. 15-39, jul./dez. 2015.

SCHNEIDERS, C. M. Serafim da Silva Neto: entre a constituição e a circulação do conhecimento linguístico. 2014. 218f. Tese (Doutorado em Letras) - Universidade Federal de Santa Maria, Santa Maria, RS, 2014.

STUMPF, I. R. C. Passado e futuro das revistas científicas. Ciência da Informação, Ibict: Brasília-DF, v. 25, n. 3, 1996.

. Revistas universitárias brasileiras: barreiras na sua produção. Transinformação, Campinas, v. 9, n. 1, p. 45-57, jan./abr., 1997.

. Reflexões sobre as revistas brasileiras. Intexto: Revista do Programa de Pós-Graduação em Comunicação e Informação da UFRGS, Porto Alegre, v. 1, n. 3, p. 1-10, jan./jun., 1998.

Recebido em 05/01/2017. Aceito em 05/04/2017. 